\title{
FORMAÇÃO DE PROFESSORES: LICENCIATURA EM QUIMICA HUMANIZADA SOB A ÓTICA DOS ALUNOS DA UNB
}

\author{
TEACHER EDUCATION: DEGREE IN HUMANIZED CHEMISTRY FROM THE \\ PERSPECTIVE OF UNB STUDENTS
}

DOI: http://dx.doi.org/10.23926/RPD.2526-2149.2020.v5.n1.p193-213.id571

\section{Evelyn Jeniffer de \\ Lima Toledo \\ Doutora em Química \\ (UFSCAR) \\ Professora na Universidade \\ de Brasília (UnB) \\ jeniffer.toledo@gmail.com}

\section{Henrique do \\ Nascimento Coutinho \\ Graduando em licenciatura \\ em Química (UnB) \\ henricoten@gmail.com}

Resumo: Entre as questões caras à pesquisa de formação de professor destaca-se o perfil do ser docente. Entretanto, pouco se tem falado sobre percebê-lo como um ser humano. Assim, o objetivo deste trabalho foi chamar a atenção para a urgência de discutir uma direção para a humanização. Apontamos a teoria das necessidades psicológicas básicas como um caminho. Foi analisado se o curso de licenciatura em química tem fomentado os pilares básicos da humanização promovendo a saúde mental dos discentes. Os dados foram obtidos através de questionário Likert e entrevista semiestruturada. A amostra foi escolhida por conveniência e julgamento. $O$ questionário teve sua adequabilidade aferida estatisticamente e aponta para uma maioria percebendo o curso como um espaço humanizado. Entretanto, a humanização não deve se restringir à maioria, mas ser estendida para todos e todas. Dessa forma, foram feitos alguns apontamentos a fim de tornar o ambiente mentalmente saudável a toda a comunidade.

Palavras-chave: Competência; Pertença; Autonomia, Saúde mental.

\begin{abstract}
Among the issues that are important to teacher education research, the profile of being a teacher stands out. However, little has been said about perceiving him as a human being. Thus, the objective of this paper was to draw attention to the urgency of discussing a direction for humanization. We point to the theory of basic psychological needs as a path. It was analyzed whether the course in Chemistry $(\mathrm{UnB})$ has been fostering the basic pillars of humanization by promoting students 'mental health. The data were obtained through a Likert questionnaire and semi-structured interview. The sample was chosen for convenience and judgment. The questionnaire has its suitability assessed statistically and points to a majority perceiving the course as a humanized space. However, humanization should not be restricted to the majority, but should be extended to everyone. Thus, some notes were made in order to make the environment mentally healthy for the whole Community.
\end{abstract}

Keywords: Competence; Belonging; Autonomy; Mental health. 


\section{INTRODUÇÃO}

A discussão sobre formação de professores é tema recorrente na área de Ensino de Química constituindo-se em uma grande linha de pesquisa que cresce e se desenvolve a cada ano (RAZERA; MATOS; BASTOS, 2019). Entre os diversos temas que abarca, podemos citar três modelos que melhor caracterizam o professor segundo Ferreira e Kasseboehmer (2012): (1) Professor Tecnicista; (2) Professor Reflexivo; (3) Intelectual Crítico.

O paradigma do professor tecnicista conhecido como racionalidade técnica (FERREIRA; KASSEBOEHMER, 2012), predominante no século XIX e XX, originou-se do positivismo do século XIX (DALL'ORTO, 1999), quando o pressuposto era de que o conhecimento científico era a própria verdade, não havendo um caminho para o progresso que diferisse das etapas estabelecidas pelo Método.

Um grande problema da formação tecnicista é que situações que fujam do arcabouço do docente, ou seja, que não foram contempladas no "manual”, irão deixá-lo perdido projetandoo para situações de fuga ou escape (BOCK; FURTADO; TEIXEIRA, 2001). Esse fato é comum tendo em vista que não vai existir uma metodologia única que atenda todas as necessidades. Portanto, a impressão será de que a formação de nada serviu, pois na prática, a teoria não teria sido útil (FERREIRA; KASSEBOEHMER, 2012).

No paradigma da racionalidade prática, predominante no século XX, emerge o modelo de professor reflexivo que rompe com o ideal de um processo de ensino por meio de um manual científico. Nesse caso, o docente reconhece que dificuldades vão surgir e que essas não serão superadas através de uma técnica infalível. Desse modo, a fim de contribuir positivamente para a superação do fracasso acadêmico, esse professor investiga a própria prática, o que possibilita que ele se torne cada vez mais consciente, substituindo a ação pelo hábito pela ação com um propósito (DORIGON; ROMANOSKI, 2008). Nesse caso, o professor percebe que um conjunto de regras sistematizadas tecnicamente não será suficiente para agir no dia a dia (SOUZA, 2007).

Embora o professor reflexivo deva ser essencialmente diferente do professor tecnicista, Zeichner (1993) citado por Ferreira e Kasseboehmer (2012) acredita que o termo foi esvaziado por falta de especificidade sobre o que refletir. Segundo o autor, a reflexão será vazia toda vez que acontecer sem que haja participação dos outros agentes envolvidos no processo, tais como alunos e comunidade; quando o foco for as estratégias de ensino em detrimento dos objetivos e quando acontecer sem que haja preocupação real com caminhos para mudanças estruturais. 
Diante dessa questão, a crítica é de que a reflexão pode ficar limitada à sala de aula, aos recursos didáticos e à forma de organização do conteúdo programático e, assim, as questões essenciais de aspectos sociais, econômicos e políticos ficariam relegadas. Portanto, reforçaríamos o discurso de neutralidade científica fazendo com que a reflexão seja apenas maquiagem, pois a essência continuaria técnica (FERREIRA; KASSEBOEHMER, 2012).

Rompendo com o modelo reflexivo, o paradigma da racionalidade crítica se manifesta. Então, emerge uma nova proposta: o modelo de professor denominado intelectual crítico.

O professor do tipo intelectual crítico, predominante no século XXI, reflete sobre a própria prática, mas também percebe o contexto da sua docência. Esse professor entende que se a mesma aula for ministrada em um bairro nobre da capital e na periferia da cidade terá resultados diferentes. Entende que isso não se refere à capacidade intelectual das turmas, mas que o significante para um contexto é diferente do que tem significado em outro, que o capital cultural dos agentes difere e que isso tem impacto na aprendizagem. O professor intelectual crítico percebe-se como agente de transformação em prol de uma sociedade melhor e para isso reflete sobre por que ensinar aquela disciplina, aquele conteúdo para aqueles estudantes e daquela forma para aquela população (FERREIRA; KASSEBOEHMER, 2012).

Embora esse modelo tenha trazido questões que ficaram apartadas do modelo reflexivo, ainda se encontra em aberto indicativos de como o professor pode se posicionar a ponto de romper com a estrutura vigente. Um caminho que vem surgindo nos últimos anos é a discussão sobre direitos humanos na formação de professores (OLIVEIRA; QUEIROZ, 2018).

A implementação da discussão sobre Direitos Humanos na formação de professores é urgente, não há como pensar em uma sociedade melhor sem a preocupação de que seja melhor para todos e todas. Entretanto, nossa proposta é que esse debate não pode se restringir ao nível de conteúdo, afinal quão longe poderemos ir humanizando os conteúdos enquanto preterimos o Ser Docente? Como seremos capazes de olhar com compaixão para os indivíduos nos distintos contextos se não conseguimos nos olhar como Seres Humanos? Como perceber nossos discentes como pessoas que sentem, que têm necessidades e que têm limites se não conseguimos ter esse olhar diante do espelho? Podemos formar intelectuais críticos, mas se antes de olharmos para o outro não formos capazes de olharmos para nós mesmos, corremos o risco de nos tornarmos mentalmente tão debilitados que, diante das agruras da prática diária, venhamos a adoecer. Dessa forma, o objetivo desta pesquisa é trazer para o debate um novo paradigma, o do professor Intelectual Crítico Humanizado. 
O ser docente Intelectual Crítico Humanizado reflete sobre sua prática de forma embebida do contexto visando mudanças estruturais no entorno enquanto desenvolve um olhar amoroso para si. Essa humanização urge cada vez mais com os alarmantes dados sobre adoecimento mental.

O adoecimento mental, como a depressão e a síndrome de Burnout, é característica marcante no século XXI. Segundo Han (2015), essas doenças, ditas neuronais, são resultado da mudança estrutural ocorrida em uma sociedade que abandonou o modelo disciplinar com os "sujeitos de obediência" de Foucault para se tornar a sociedade do desempenho e produção. Dessa forma, onde antes predominava a proibição e a negação de direitos vigora a necessidade de produtividade. Vende-se a ideia de que tudo é possível, basta querer e se esforçar. De tal modo, o sujeito de desempenho entra em guerra consigo ficando exaurido. De forma alguma Han (2015) defende o modelo disciplinar, apenas aponta que os loucos e delinquentes estão sendo substituídos pelos depressivos e fracassados (HAN, 2015).

Para a sociedade capitalista esse novo modelo é muito mais eficiente, pois enquanto a “disciplina” em determinados níveis bloqueia, impedindo o crescimento, o sujeito "positivo" é produtivo sendo mais disciplinado. O novo indivíduo do século XXI por acreditar que tudo depende da sua dedicação "decide" realizar diversas atividades simultaneamente e assim se sente capaz. O Capital enxerga essa nova forma de viver como um sinal de progresso, porém Han (2015) argumenta que essa visão é ilusória, pois o indivíduo, agora multitarefado, retrocede aos primórdios da civilização na qual precisava de atenção múltipla para garantir a sobrevivência. Dessa forma, embora consiga executar várias tarefas em tempo recorde, o faz de forma rasa não conseguindo mergulhar com profundidade em nada. Assim, essa sociedade que era de obediência foi se transformando na sociedade do desempenho e a cada dia se transforma mais em sociedade do cansaço que diariamente caminha para se tornar a sociedade do doping. Afinal, somente dopados conseguiremos continuar nesse ritmo desumanizante.

A crueldade dessa sociedade do desempenho foi relatada por Brant, Minayo-Gomez, (2008). Os autores, ao entrevistarem trabalhadores, observaram que muitos receavam ir ao médico por medo de que fossem receitados antidepressivos, o que poderia ser visto como prova de fracasso, incompetência e desadaptação. Ademais, não há como negar que muitos são medicados sem real necessidade, afinal silenciar as dores da alma para que os sujeitos continuem trabalhando também é característica dessa sociedade "moderna".

A vida na Universidade não é melhor do que a na sociedade apontada por Han (2015) ou por Brant e Minayo-Gomez (2008). Professores e alunos vivem uma pressão diária para 
aumentarem sua produtividade (RÔÇAS; ANJOS; PEREIRA, 2017; ROMÃO, 2019), Covas e Veiga (2016) apontam que a saúde mental dos estudantes é ainda pior do que da sociedade em geral. No caso dos discentes, é preciso destacar que o ingresso na universidade acontece, muitas vezes, no período de transição da adolescência para vida adulta (CORTEZ et al, 2017). Ademais, sem perceber o próprio adoecimento e a gravidade de seu estado ou por não ter fonte de apoio, o aluno acaba ignorando os sinais e agravando a situação, pois ao guardar os sentimentos pode entrar em um processo de "ruminação" (ARAUJO et al, 2016). Dessa forma, não falar sobre os problemas não faz com que eles deixem de existir, pelo contrário, pode acentuá-los ao dificultar o acesso à ajuda especializada podendo culminar em tentativas ou até efetivação de suicídio (BARBOSA; MACEDO; SILVEIRA, 2011).

Os dados da Organização Mundial de Saúde (OMS, 2019) apontam que a cada 40 minutos uma pessoa comete suicídio no Brasil e esta é a segunda maior causa de morte entre jovens de 15 a 24 anos, a primeira são os acidentes de trânsito. É necessária atenção redobrada para com aqueles que já tentaram suicídio, não como forma de estigmatizar, mas como prevenção, pois dos que atentaram contra própria vida entre 15 a $25 \%$ tornarão a fazê-lo no ano seguinte e desses 10\% irão conseguir nos próximos 10 anos. (BOTEGA, 2002 apud BARBOSA; MACEDO; SILVEIRA 2011). Além disso, é preciso considerar que os dados da OMS estão subestimados, pois nem sempre é possível diferenciar o acidente da ação intencional.

Nessa perspectiva, é preciso que falemos, de forma responsável, se quisermos mudar as estatísticas (BARBOSA; MACEDO; SILVEIRA 2011), pois não há mais como achar normal que o excesso de atividades acadêmicas continue impedido o estudante de ter momentos de lazer. Não é normal que o aluno pare somente quando o corpo não resiste mais (CORTEZ et al, 2017), afinal são esses sujeitos adoecidos que, no caso da licenciatura, serão colocados em salas de aula por todo o país reproduzindo esse paradigma debilitante. Assim, enquanto formadores de professores, temos a obrigação ética de avançarmos para a discussão de um Ser Docente Intelectual Crítico Humanizado que ao olhar amorosamente para si aceita que não é uma máquina de produzir com peças substituíveis mediante alguma falha. Não é aceitável que continuemos a nos calar diante dos dados que surgem na nossa frente. Só no Estado de São Paulo, Arcoverde et al (2017) por meio da lei de acesso à informação apontam que 37\% dos dias de afastamento de professores da educação básica no Estado de São Paulo em 2016 foram por questões de saúde mental. 
Diante do exposto, acreditamos que é preciso reconhecer a saúde mental como pilar básico na formação de professores, afinal são docentes adoecidos e/ou em situação de risco que queremos colocar nas salas de aula por todo o país? Portanto, defendemos que a humanização da sociedade se inicie na humanização dos cursos de formação de professores. Dessa forma, a fim de contribuir com esse discurso, esta pesquisa faz uso da teoria das necessidades psicológicas básicas (NPB) (DECI; RYAN, 2002), uma subteoria da Teoria da Autodeterminação (DECI; RYAN, 1985) para debater um caminho para a humanização dos futuros docentes.

\section{REFERENCIAL TEÓRICO: TEORIA DAS NECESSIDADES PSICOLÓGICAS BÁSICAS}

A teoria das necessidades psicológicas básicas é alicerçada por três pilares, são eles: competência, autonomia e pertença (DECI; RYAN, 2002).

A competência está atrelada à percepção da capacidade em realizar com maestria o que decidir executar. Dessa forma, quando o indivíduo realiza de modo bem sucedido aquilo que se propôs a fazer, ele tem a sua percepção de competência fortalecida. Do mesmo modo, quando as ações realizadas se embebem continuamente de um sentimento de inadequação/fracasso, a percepção de competência é minada.

A autonomia refere-se à percepção que o indivíduo tem sobre agir segundo suas próprias decisões. Nesse caso, é fortalecida sempre que o aluno se encontrar em espaços onde tem voz, assumindo controle sobre suas escolhas, portanto, agindo da forma que decidiu agir e não porque foi obrigado/controlado/manipulado para realizar determinada ação. Por outro lado, em ambientes onde as ações são determinadas por meio de coação física ou psicológica, esse sentimento é aniquilado.

A percepção de pertença está relacionada com a construção de vínculos que o indivíduo realiza. Portanto, um ambiente que favorece a formação de laços significativos fortalece a percepção de pertença. Entretanto, ela será enfraquecida em espaços onde o indivíduo sente que não é bem-vindo.

A nutrição dos pilares psicológicos básicos de um indivíduo irá fomentar a motivação dos sujeitos (DECI; RYAN, 2002), o que a princípio, deve favorecer a saúde mental, ao mesmo tempo em que a alienação desses pilares irá contribuir para a desmotivação do indivíduo colaborando para que ele se direcione para um estado risco mental.

Podemos afirmar que a forma do ambiente em que um curso de licenciatura se efetiva irá contribuir negativa ou positivamente para a saúde mental de sua comunidade. Por exemplo, 
o sucesso na execução de ações que não sejam fáceis a ponto de se tornarem desinteressantes, nem difíceis a ponto de não serem factíveis permite que o estudante desenvolva uma visão positiva sobre sua capacidade cognitiva. Dessa forma, quando o curso proporciona atividades que se encontrem em um nível adequado de dificuldade, os indivíduos terão sua percepção de competência fortalecida tornando-se mais motivados e mentalmente saudáveis. Além disso, quando o curso é construído de modo a estimular a existência de espaços onde haja diálogo entre seus membros, culminando em uma gestão democrática, o sentimento de autonomia é fortalecido. Portanto, debater as formas de ensino e aprendizagem, de avaliação, a construção do currículo são possibilidades que podem contribuir para a percepção de autonomia dos discentes gerando um clima mais saudável. Ademais, um espaço onde a população possa construir laços de amizade passando a vivenciar relações de afeto nutrirá o sentimento de pertença dos indivíduos tornando o espaço acolhedor.

De tal modo, podemos vislumbrar que um curso onde temos ações que promovam o sentimento de competência, autonomia e pertencimento entre seus membros é um ambiente promotor de saúde mental que contribuirá com a formação do ser docente intelectual crítico humanizado que almejamos.

Portanto, acreditando que precisamos humanizar nossos licenciandos para além dos conteúdos e tendo como referencial a teoria das necessidades psicológicas básicas, esta pesquisa investigou se o Curso de Licenciatura em Química da Universidade de Brasília tem proporcionado a nutrição desses pilares de forma a fomentar a saúde mental dos futuros professores.

\section{Metodologia}

A pesquisa é do tipo mista associando instrumento quantitativo e qualitativo na obtenção dos resultados (DAL-FARRA; LOPES, 2013).

O instrumento quantitativo refere-se a um questionário psicométrico (GUIMARÃES, 2003; TOLEDO, 2015) para mensurar as necessidades psicológicas básicas dos sujeitos. Ele foi desenvolvido por Engelmann (2010) tendo sido adaptado por Toledo, Coutinho e Galdino (2019) e é composto por 34 questões do tipo Likert com 5 pontos. Cada aplicação durou aproximadamente 30 minutos.

Os sujeitos analisados são pertencentes ao curso de Licenciatura em Química da Universidade de Brasília. A população é de 259 estudantes regularmente matriculados, a 
amostragem é por conveniência, totalizando 105 discentes. O curso é noturno sendo composto por 232 discentes com até 24 anos.

A adequabilidade da população foi verificada através do teste Kaiser-Meyer-Olkin (KMO) e do teste de esfericidade de Bartlett. O questionário teve sua validade aferida através da análise fatorial exploratória com o método de componentes principais e rotação varimax. A confiabilidade foi verificada através do cálculo do alfa de Cronbach. Os dados foram submetidos a análise de normalidade (teste de Kolmogorov-Smirnov) $e$ as medianas foram comparadas (teste de Wilcoxon). Os cálculos foram realizados para uma confiança de $95 \%$.

O instrumento qualitativo foi uma entrevista semiestruturada para alguns dos estudantes que haviam respondido o questionário inicial a fim de permitir que pudéssemos fazer um aprofundamento da discussão. Nesse caso, a amostragem é por julgamento, pois foram escolhidos alunos que apresentaram valores extremados em alguns dos constructos. A entrevista foi gravada e posteriormente transcrita e as respostas foram analisadas fazendo uso da análise de conteúdo proposta por Bardin (2011). Portanto, foi feita inicialmente uma leitura flutuante selecionando os trechos que seriam analisados profundamente. Tendo em mente, aprioristicamente, os constructos de interesse, as unidades de significado foram enquadradas nas categorias (CAMPOS, 2004).

\section{Resultados}

Considerando a análise fatorial exploratória pelo método das componentes principais com rotação varimax e o cálculo da confiabilidade pelo teste do alfa de Cronbach, foram removidas algumas questões do questionário a fim de garantir que a validade e a confiabilidade dele fosse a mais proeminente possível. Para o questionário resultante foi realizado o teste KMO e o de esfericidade de Bartlett gerando 0,838 e p=0,000, respectivamente. Dessa forma, percebe-se que a amostra se mostrou adequada.

Em relação à análise fatorial exploratória do questionário final, a matriz pode ser visualizada no Quadro 1.

Quadro 1 - Matriz fatorial exploratória

\begin{tabular}{|c|c|c|c|}
\hline Questão & Competência & Pertencimento & Autonomia \\
\hline $\mathbf{1 3}$ & 0,74 & & \\
\hline $\mathbf{2 3}$ & 0,74 & & \\
\hline $\mathbf{3 2}$ & 0,73 & & \\
\hline $\mathbf{1 6}$ & 0,71 & & \\
\hline
\end{tabular}




\begin{tabular}{|c|c|c|c|}
\hline $\mathbf{1 5}$ & 0,69 & & \\
\hline $\mathbf{7}$ & 0,66 & & \\
\hline $\mathbf{8}$ & 0,60 & & \\
\hline $\mathbf{2 0}$ & 0,60 & & \\
\hline $\mathbf{2}$ & 0,48 & & \\
\hline $\mathbf{2 6}$ & 0,45 & & \\
\hline $\mathbf{2 2}$ & & 0,82 & \\
\hline $\mathbf{6}$ & & 0,80 & \\
\hline $\mathbf{2 5}$ & & 0,80 & \\
\hline $\mathbf{2 8}$ & & 0,78 & \\
\hline $\mathbf{1 2}$ & & 0,76 & 0,49 \\
\hline $\mathbf{1 8}$ & & 0,66 & 0,70 \\
\hline $\mathbf{3}$ & & 0,61 & 0,69 \\
\hline $\mathbf{1 1}$ & & & 0,61 \\
\hline $\mathbf{3 4}$ & & & \\
\hline $\mathbf{2 9}$ & & & \\
\hline $\mathbf{4}$ & & & \\
\hline $\mathbf{9}$ & & & \\
\hline
\end{tabular}

Fonte: os autores

Na primeira coluna, são apresentadas as questões analisadas. Elas foram ordenadas de forma agrupada para cada constructo e com os pesos em ordem decrescente para que as observáveis com maior impacto ficassem destacadas. Os valores inferiores a 0,4 foram suprimidos como havia sido recomendado por Hair et al (2006) citado por Ariani (2013).

A classificação quanto à relevância das cargas foi apontada por Guimarães (2003) e pode ser visualizada no Quadro 2.

Quadro 2 - Classificação qualitativa da carga fatorial
\begin{tabular}{|c|c|c|}
\hline Muito baixo & Moderada & Alto \\
\hline Fator $<0,3$ & $0,30<\alpha \leq 0,60$ & fator $>0,60$ \\
\hline
\end{tabular}

Fonte: adaptado de Guimarães (2003)

Dessa forma, podemos perceber que apenas 3 questões apresentaram carga fatorial no nível moderado. As demais são classificadas como altas. Portanto, sugerimos que outros autores 
realizem pequenas alterações nas questões de menor carga a fim de verificar se elas podem ser melhoradas.

Com a análise fatorial validando os constructos analisados, os dados foram submetidos a análise de confiabilidade através do cálculo do alfa de Cronbach que varia entre 0 e 1 segundo Araujo (2009), tendo classificação de 5 pontos conforme indica Freitas e Rodrigues (2005) (Quadro 3).

Quadro 3 - Classificação qualitativa do alfa de Cronbach

\begin{tabular}{|c|c|c|c|c|}
\hline Muito baixo & Baixo & Moderado & Alto & Muito Alto \\
\hline$\alpha \leq 0,3$ & $0,3<\alpha \leq 0,6$ & $0,6<\alpha \leq 0,75$ & $0,75<\alpha \leq 0,90$ & $\alpha>0,90$ \\
\hline
\end{tabular}

Fonte: Freitas e Rodrigues (2005)

Os valores obtidos conjuntamente com as questões correspondentes podem ser visualizados na Quadro 2.

\begin{tabular}{|c|c|c|c|}
\hline Quadro 4 - Alfa de cronbach para os constructos \\
\hline Constructo & Questões & Alfa de Cronbach & Mediana \\
\hline Competência & $2,7,8,13,15,16,20,23,26,32$ & 0,86 & 3,50 \\
\hline Autonomia & $4,9,11,29,34$ & 0,88 & 4,00 \\
\hline Pertença & $3,6,12,18,22,25,28$ & 0,73 & 4,00 \\
\hline
\end{tabular}

Fonte: os autores

Com os valores obtidos para o alfa de Cronbach, podemos perceber que os dados possuem consistência adequada para inferências qualitativas acerca dos indivíduos estudados. Dessa forma, estatisticamente, o instrumento utilizado se mostrou confiável para exploração qualitativa sobre a nutrição das NPB dos estudantes averiguados.

Para analisar os constructos, os dados foram submetidos ao cálculo da mediana (Tabela 2). A escolha da mediana é mais adequada do que a análise da média em casos onde a análise é feita sobre dados de uma escala como a Likert (TOLEDO, 2015).

Para comparar as medianas foi realizado, o cálculo de normalidade através do teste de Kolmogorov-Smirnov. Como resultado, o $p$ de todos os constructos foi igual a 0,000. Portanto, os dados não seguiram uma distribuição normal. Então, a mediana foi comparada através do teste de Wilcoxon conforme pode ser verificado na Quadro 5. 
Quadro 5 - Teste de Wilcoxon para os constructos motivacionais

\begin{tabular}{|c|c|c|}
\hline Constructos & $\mathbf{Z}$ & $\mathbf{p}$ (2 extremidades) \\
\hline Competência x Autonomia & $-1,852$ & 0,064 \\
\hline Competência x Pertença & $-1,486$ & 0,138 \\
\hline Autonomia x Pertença & $-0,866$ & 0,397 \\
\hline
\end{tabular}

Fonte: os autores

Como é possível observar, pelo valor de p maior que 0,05 em todos os casos, a comparação entre todos os fatores não se fez diferente. Dessa forma, estatisticamente a nutrição do fator competência, autonomia e pertença foi equivalente para a população estudada.

O valor de aproximadamente 4 obtido para competência, autonomia e pertença é um indicativo de que o curso tem sido estruturado de forma a fornecer um ambiente saudável aos seus alunos. Isso não significa que a acolhida acontece de forma equivalente para todos os estudantes, alguns tem sua motivação menos ou mais nutridas, fatores esses que podem ser observados pela análise das respostas à entrevista semiestruturada.

\section{-Competência}

Em relação à percepção de competência os estudantes foram indagados se eles acreditam estarem indo bem nas atividades avaliativas do curso, se confiam que vão se tornar bons profissionais e se creem que são capazes de iniciar algum projeto sem o professor.

\section{-Desempenho nas atividades avaliativas;}

Os alunos que apontaram uma percepção de competência maior do que o ponto de neutralidade indicaram que, de forma geral, tem um desempenho positivo, enquanto os que estavam abaixo do ponto de neutralidade afirmaram que o desempenho vem sendo negativo. Em ambos os casos, atribuíram insucessos em disciplinas por conta de má formação no ensino médio, quantidade de disciplinas que precisam fazer por semestre e o nível de exigência de alguns professores. Neste último caso, um estudante relatou que a sua formação deficitária na educação básica vem sendo agravada nas aulas de um professor que além de não se fazer entender, adota como texto base um livro em inglês. Podemos perceber, nesse caso, evidência de comportamento tecnicista quando o professor não percebe ou não se importa em fazer uso de um material de ensino que não condiz com a realidade dos discentes.

Ademais, os alunos com baixa percepção de competência afirmaram que estão tentando melhorar o desempenho e para isso estão tentando diminuir o número de disciplinas por semestre e escolhendo aquelas mais fáceis de se obter aprovação. Além disso, estão trancando quando percebem que serão reprovados. Por fim, eles se lamentam por reconhecer que em 
algumas matérias a dificuldade não é vencida por mais que estudem. Nesse caso, assumem para si a dificuldade, o que pode contribuir para percepção de inadequação ao curso.

Os alunos com boa percepção de competência ainda afirmaram que atribuem o bom desempenho à boa formação que tiveram no ensino médio e à afinidade com os conteúdos do curso. Quando o desempenho não é o esperado, a razão é delegada ao professor e seu sistema avaliativo. Quando assumem parte da culpa, esta está relacionada com a falta de dedicação ao estudo preservando sua autoimagem.

Um fator interessante é que os alunos, independente da percepção de competência, afirmaram que raramente pesquisam outra fonte que não seja o texto base utilizado pelo professor e quando o fazem, a escolha é por conteúdo da internet.

\section{-Perspectiva em ser um bom professor;}

Em relação a se tornarem bons professores, os alunos que apresentaram competência igual ou acima do ponto de neutralidade relataram terem convicção de que serão, acrescentaram que sentem que o curso está preparando-os isso e apontam como evidência o desempenho percebido em atividades como o Programa Institucional de Bolsas de Iniciação à Docência (PIBID) e monitorias nas disciplinas de graduação e/ou em escolas de nível médio.

Os que apresentam nota abaixo da média afirmaram que vão tentar e esperam conseguir. Acreditam que estão se esforçando para isso, mas não há garantia.

\section{-Percepção sobre a competência em desenvolver um projeto;}

De forma unânime, nenhum dos estudantes relatou acreditar ser possível desenvolver algum projeto sem auxílio de um professor, entretanto, aqueles com alto nível de percepção de competência afirmam que já estão inseridos em atividades extracurriculares como PIBID, extensão ou iniciação científica e quando não estão, atribuem a falta de tempo por já estarem trabalhando. Por outro lado, os alunos com baixa percepção de competência não pensam em participar dessas atividades nos próximos anos ou afirmam nunca terem refletido sobre o assunto.

\section{-Autonomia}

A percepção de autonomia gerou uma mediana de 4 para a população estudada. A fim de aprofundá-la, os alunos foram questionados sobre como escolhem as atividades que fazem no curso, se se sentem livres para escolherem, se já participaram de algum tipo de projeto e como essa participação aconteceu.

\section{-Escolha das atividades}


Em relação à escolha das atividades, os alunos elogiaram a flexibilização de currículo que a UnB exige em suas regras internas. O currículo não pode ser construído em cima de uma grade fechada, de forma que $30 \%$ deve ser composto por disciplinas livres. Assim, os alunos podem conhecer outros departamentos e unidades vivenciando novas experiências.

A escolha da disciplina baseada na curiosidade, interesse pela área, percepção de que vão melhorar sua competência profissional com a aprendizagem do conteúdo presente na ementa foi apontada por alunos que apresentaram competência acima da média, enquanto os demais afirmaram escolher de acordo com a facilidade em obter aprovação.

Dessa forma, estudantes com a percepção de competência mais elevada sentem-se mais livres para escolher as atividades curriculares e, portanto, alimentam a percepção de autonomia, enquanto aqueles que apresentam dificuldade acabam tendo o rol de opções reduzidas.

Entretanto, apesar de $30 \%$ do currículo ser livre, existem algumas disciplinas de cunho obrigatório. Entre os entrevistados, tivemos uma estudante que se manifestou indignada por não entender a razão de determinada disciplina ser imperativa tendo pré-requisito incoerente e sendo um pré-requisito desnecessário para as demais, segundo a opinião da discente. De acordo com o relato da aluna, o problema não era o fato de a disciplina ser obrigatória, mas a falta de explicação para suas inquietações. Sendo assim, podemos perceber que a questão não é a aluna ter que cursar disciplina $\mathrm{A}$ ou $\mathrm{B}$, mas a verticalidade e a falta de diálogo com os formadores. Esta estudante, embora tenha apresentado nível de competência alto, demonstrou nível de autonomia baixo.

\begin{abstract}
Aluna: Desde o início da disciplina eu sempre questionei qual que era a importância daquela disciplina e porque que ela era um pré-requisito de outras disciplinas do ensino, entendeu? E essa pergunta o professor nunca me respondeu. Até hoje. Então, assim, eu fiz uma disciplina que eu não estava feliz, que eu não era feliz, que não me acrescentou em nada porque não fez diferença na minha vida. A única diferença que fez foi porque eu posso cursar outras disciplinas do ensino que dependiam dela, entendeu?
\end{abstract}

A resposta da estudante nos faz questionar sobre o paradigma que o docente adota, de forma consciente ou não. A falta de diálogo, a verticalidade da postura nos leva a crer que o tecnicismo é mandatório nesse caso. Portanto, como esperar que o curso forme estudantes humanizados se eles não são tratados como dignos de uma resposta? A resposta clara pode não existir, o currículo pode ter sido construído sem a anuência do docente em questão, talvez ele nunca tenha se questionado sobre a própria disciplina, mas um professor intelectual crítico humanizado olha para si amorosamente e assume que não tem todas as respostas e que estas podem ser construídas em colaboração com a sala e/ou demais colegas. Um professor 
intelectual crítico humanizado se destitui do autoritarismo e deixa a amorosidade fazer com que ele se permita não saber e, permitindo ensina à aluna que ele é humano e que ela também pode ser.

Além disso, a aluna chama atenção para o fato de que algumas disciplinas que existem na universidade não podem ser cursadas por todos os estudantes porque as vagas são restritas a determinados cursos.

\section{-Participação em projetos}

Os estudantes que participam ou participaram de projetos unanimemente relataram terem sua percepção de autonomia vinculada à postura do professor orientador. Um exemplo dessa questão é o de uma estudante que tendo participado de 3 projetos distintos com professores diferentes se sentiu autônoma em apenas um. Segundo a aluna, somente uma orientadora levava em consideração o que ela externava argumentando a escolha dos percursos metodológicos. Com os demais, ela se sentia obrigada a fazer o que mandavam, mesmo não concordando. Dessa forma, no momento que o contrato findava e ela tivesse terminado de cumprir suas obrigações abandonava a ação, pois não estava feliz.

Um apontamento recorrente aconteceu entre os alunos que participam do PIBID: esses estudantes relataram que essa era uma das melhores experiências na universidade, pois não se sentiam apenas competentes, mas autônomos podendo fazer as escolhas com a certeza de serem reconhecidos e ouvidos tanto pelo supervisor da Universidade quanto pelo professor da educação básica.

\section{-Pertencimento}

Em relação ao pertencimento que gerou uma mediana de 4, os estudantes foram questionados sobre a relação deles com os colegas, se tinham amigos na universidade e fora dela. Se gostavam das pessoas e se desejavam que as relações se estabelecessem de forma diferente.

\section{-Relação com os colegas}

Os alunos que apresentaram índices altos de pertença relataram que na faculdade estabeleceram boas relações tendo alguns amigos que consideram como verdadeiros ultrapassando as fronteiras da universidade. Esses discentes atribuíram essa boa relação à facilidade com que fazem amizade em razão de sua natureza. Alguns, inclusive, tinham a amizade estabelecida desde o Ensino Médio, permanecendo após ingressarem na universidade. 
Aqueles que apresentaram um sentimento de pertença no ponto de neutralidade responderam que tem colegas, pessoas que gostam, mas não têm amizades. Atribuem isso à dificuldade em estabelecer relações profundas.

Alunos que apresentaram sentimento de pertença abaixo do ponto de neutralidade afirmaram não terem amigos na universidade e atribuíram isso à timidez e/ou dificuldade de se relacionar com as demais pessoas.

Uma estudante chamou nossa atenção pela forma contundente de se posicionar. Essa aluna apresentou nível de pertencimento igual a 2. Disse que a maioria dos outros discentes eram apenas colegas, que uma minoria poderia ser considerada amiga. Afirmou, várias vezes na entrevista, que isso era resultado da sua personalidade, do seu jeito de se posicionar e que diante disso já tinha ouvido, várias vezes, que os outros não gostavam dela. Ao ser indagada sobre como ela se posicionava, a aluna alegou que era excessivamente sincera de um jeito errado, mas não se importava porque o objetivo não era fazer amigos, mas se formar.

\section{-Relação com o ambiente externo à universidade}

De forma geral, todos os estudantes afirmaram terem boas relações do lado de fora, inclusive aqueles que apresentaram baixa percepção de pertença. No caso dos estudantes com dificuldade de relacionamento na universidade, estes afirmaram que os amigos que tinham fora da universidade eram suficientes, que não sentiam falta e que não tinham tempo a perder tentando estabelecer novas relações

\section{-Satisfação com a forma de relação}

Dessa forma, os alunos que indicam terem estabelecido boas relações dentro da universidade, como era de esperar, estão satisfeitos com as amizades construídas. Porém, aqueles que afirmaram terem muita dificuldade de relacionamento também afirmaram satisfeitos, ao menos no nível consciente, repetindo inúmeras vezes que não precisam de mais ninguém. Infelizmente não é possível, nessa pesquisa, afirmar se esses alunos de fato não se sentem sozinhos na vida acadêmica e se esse discurso de não precisar do outro foi uma forma de proteger a autoimagem.

Nessa perspectiva, considerando os resultados apresentados, pudemos perceber, por meio das análises estatísticas, que o instrumento utilizado se mostrou adequado à população estudada permitindo que fossem feitas inferências qualitativas. Foi constatado que os estudantes investigados do curso de Licenciatura em Química da UnB apresentaram alta percepção de competência, pertencimento e autonomia o que configura um fôlego para nós formadores de professores diante de uma sociedade cada vez mais doente (OMS, 2019). Porém, como 
esperado, essa percepção não é equivalente para todos, alguns situam-se no extremo oposto. A fim de melhor compreendê-los e construir ações para auxiliá-los, foram realizadas entrevistas semiestruturadas que apontaram para a necessidade de criarmos um projeto que possa sanar as dificuldades oriundas da educação básica, pois foram as relações com as disciplinas do ensino médio que mais impactaram a percepção de competência dos investigados.

Avaliando as questões referentes à autonomia e pertencimento concomitantemente com a baixa percepção de competência, acreditamos que um projeto ideal seria um clube de ciências ou algo nos moldes do PIBID, porém com foco nos alunos do ensino superior. Assim, além de contribuirmos para a superação das dificuldades básicas das questões relacionadas à química, física e matemática estaríamos formando um grupo que, caso seja conduzido de modo adequado, pode ser um ambiente propício para o estabelecimento de relações significativas de amizade. Além disso, a escolha dos temas e atividades desenvolvidas pode ser realizada pelos próprios estudantes a fim de fomentar o sentimento de autonomia. A participação no projeto poderá ocorrer de duas formas, mediante a solicitação do aluno ou por convite, pois acreditamos que ao convidar alguns alunos reforçaremos o sentimento de pertença e competência. $\mathrm{O}$ grupo, a priori, deverá ser heterogêneo ou seja, constituído por alunos com baixa e alta percepção de competência, pertença e autonomia de forma a não estigmatizá-lo como "grupo de alunos com dificuldades". Portanto, o instrumento aqui validado pode ser um recurso na identificação de possíveis membros do grupo.

Outras questões também foram percebidas como possíveis fontes para a nutrição da saúde mental dos discentes. São elas:

-Junção de disciplinas a fim de reduzir o número de matérias necessárias a serem cursadas por semestre o que, consequentemente, diminuirá o número de atividades a serem desenvolvidas possibilitando que tenham mais tempo para se dedicarem com profundidade saindo da corrida multitarefada exposta por Han (2015).

-Criação de material didático próprio e em português que possa ser disponibilizado tanto na versão impressa quanto digital;

-Rodas de conversa com o coordenador do curso a fim de dialogar sobre a importância das disciplinas obrigatórias, sua posição no currículo e os pré-requisitos. Ademais, essa roda precisa acontecer de forma democrática no sentido de abrir possibilidade para que sugestões advindas dos estudantes sejam incorporadas à matriz curricular. Entre as sugestões, os alunos podem ser instigados a construírem uma lista das disciplinas de interesse que sejam oferecidas pela universidade que se encontram como restritas. Após a análise da pertinência da lista, o 
coordenador pode realizar uma tentativa, junto à unidade responsável, de solicitar abertura de algumas vagas para a licenciatura. A depender de uma avaliação da positividade da ação seria possível verificar a abertura de novas turmas;

-Cursos de extensão, que podem ser aproveitados como horas complementares, sobre comunicação não violenta e desenvolvimento de habilidades interpessoais permitindo que os alunos possam reconhecer outras formas de lidar com as diferenças contribuindo não apenas para a saúde mental enquanto discente, mas para o exercício da docência para que não venham a se tornar professores opressores;

Por fim, solicitamos à Secretaria de Saúde do Distrito Federal, por meio da lei de acesso à informação pública, dados referentes ao afastamento dos servidores da educação básica do Distrito Federal no ano de 2018. Como resultado, foi constatado que 40\% dos dias afastados foram ocasionados por transtornos mentais e comportamentais. Esse fato, somado aos $37 \%$ detectados por Arcoverde et al (2017) em São Paulo não deixa dúvida sobre a urgência de dialogarmos sobre como construir um ambiente acadêmico mentalmente saudável, pois não podemos continuar a esperar o adoecimento dos indivíduos para agirmos. A maioria dos alunos do curso de licenciatura em química apresentaram alto nível de percepção de competência, autonomia e pertencimento. Porém, o curso não é feito para a maioria, é feito para todos. Assim, buscar ações que possam contribuir para a saúde mental dos discentes é imprescindível na formação de um corpo social mais humanizado.

\section{CONSIDERAÇões FinaIS}

Neste artigo, trazemos à luz a importância de se discutir um modelo de formação de professores que considere o próprio professor como um ser humano. Acreditamos que não basta falar de mudanças estruturais através de conteúdos que abarquem os Direitos Humanos enquanto o docente é enxergado como uma máquina de produzir que é substituída quando falha. Assim, sob o olhar da teoria das necessidades psicológicas básicas, investigamos se o curso de Licenciatura em Química da UnB tem promovido a percepção de competência, pertencimento e autonomia em seus discentes contribuindo para a saúde mental de sua comunidade. Como resultado, foi aferido que o instrumento utilizado encontra-se estatisticamente adequado e que, de forma geral, os discentes têm sua saúde mental alimentada, entretanto, várias ações ainda devem ser realizadas a fim de promovê-la mais intensamente para todos e todas. Entre as ações apontadas, destacamos cursos de extensão que desenvolvam as relações interpessoais, a criação de programas que minimizem as deficiências acadêmicas oriundas da educação básica e rodas 
de diálogo com o corpo docente a fim de debater o currículo. Dessa forma, sugerimos que esse instrumento psicométrico possa ser utilizado por outros cursos em diferentes instituições de ensino com o objetivo de verificar a percepção de sua comunidade e intervir, com responsabilidade, junto aos discentes em situação de risco antes que tragédias aconteçam. Embora não seja função fim das instituições de ensino resolver as questões de saúde, é preciso que os cursos assumam a necessidade de cuidado com a comunidade para que não sejam cobertos de sangue.

\section{REFERÊNCIAS}

ARAÚJO, Nelci Reis Sales de; LABURÚ, Carlos, Eduardo. Uma análise da validação e confiabilidade da escala de opiniões da seleção de experimentos de química (EOSEQ). Ensaio-Pesquisa em Educação em ciências, Belo Horizonte, v.11, n.2, p.199-220, 2009. Disponível em: http://www.scielo.br/scielo.php?pid=S198321172009000200199\&script=sci_abstract\&tlng=pt. Acessado em: 04 nov 2019.

ARAÚJO, Karla Jéssica Sandos de; SILVA, Andréia Moreira da. SILVA JÚNIOS, George Martins Ney da; CARRIJO, João Batista; CAIXEIRA, Leonardo Ferreira; BAGASRA, Anisah. Sofrimento mental: avaliação em uma universidade americana. Revista educação em saúde. Anápolis, v.4, n.2, p.64-71, 2016. Disponível em:

http://periodicos.unievangelica.edu.br/index.php/educacaoemsaude/article/download/2018/18 00. Acessado em: 04 nov 2019.

ARCOVERDE, Leo; FRANCO, Elis; GALVÃO, Danielle; PRADO, Gabriel. Número de professores afastados por transtorno em SP quase dobra em 2016 e vai a 50 mil. Globo News, São Paulo. 21/11/2017. Disponível em: https://g1.globo.com/sp/sao-paulo/noticia/numero-deprofessores-afastados-por-transtornos-em-sp-quase-dobra-em-2016-e-vai-a-50-mil.ghtml. Acessado 15/10/2019.

ARIANI, Dorothea Wahyu. Personality and Learning Motivation. European Journal of Business and Management. v.5, n.10, p.26-39 2013 Disponível em: https://www.iiste.org/Journals/index.php/EJBM/article/view/5142. Acessado em: 04 nov 2019.

BARBOSA, Fabiana de Oliveira; MACEDO, Paula Costa Mosca.; SILVEIRA, Rosa Maria Carvalho da. Depressão e o suicídio. Revista da Sociedade Brasileira de Psicologia Hospitalar, Rio de Janeiro, v.14, n.1, p.233-243 2011. Disponível em: http://pepsic.bvsalud.org/scielo.php?script=sci_arttext\&pid=S1516-08582011000100013. Acessado em: 04 nov 2019.

BARDIN, Laurence. Análise de conteúdo, $1^{\text {a }}$ edição, São Paulo: Edições 70, 2011.

BOCK, Ana Mercês Bahia; FURTADO, Odair; TEIXEIRA, Maria de Lourdes Trassi. Psicologias: uma introdução ao estudo de psicologia, $13^{a}$ edição, São Paulo: Editora Saraiva, 2001. 
BRANT, Luiz Carlos; MINAYO-GOMEZ, Carlos. Da tristeza à depressão: a transformação de um mal-estar em adoecimento no trabalho. Interface, Botucatu, v.12, n. 26, p.667-676 2008. Disponível em: http://www.scielo.br/scielo.php?pid=S141432832008000300017\&script=sci_abstract\&tlng=pt. Acessado em: 04 nov 2019.

CAMPOS, Claudinei José Gomes. Método de análise de conteúdo: ferramenta para a análise de dados qualitativo no campo da saúde. Revista Brasileira de Enfermagem, Brasília, v.57, n.5, p.611-614, 2004. Disponível em: http://www.scielo.br/scielo.php?pid=S003471672004000500019\&script=sci_abstract\&tlng=pt. Acessado em: 04 nov 2019.

CORTEZ, Elaine Antunes; BRAGA, André Luiz de Souza; OLIVEIRA, Alessandra Gonçalo da Silva; RIBAS, Beatriz Folly; MATTOS, Mônica Montuano Gonçalves Ramos; MARINHO, Tatiane Glicerio; CAVALCANTI, Thayná Victório Costa; DUTRA, Virginia Faria Damásio. Promoção à saúde mental dos estudantes universitários Revista PróUniverSUS, Vassouras, v.8, n.1, p.48-54, 2017. Disponível em: http://editora.universidadedevassouras.edu.br/index.php/RPU/article/view/896/703. Acessado em: 04 nov 2019.

COVAS, Filomena; VEIGA, Feliciano. Envolvimento na escola e saúde mental dos estudantes de ensino superior: um projeto de investigação. In: CONGRESSO

INTERNACIONAL DE ENVOLVIMENTO DOS ALUNOS NA ESCOLA: PERSPETIVA DA PSICOLOGIA E EDUCAÇÃO MOTIVAÇÃO PARA O DESEMPENHO

ACADÉMICO, 2, 2016, Lisboa. Anais...Lisboa: Instituto de Educação da Universidade de Lisboa, 2016, p.978-989. Disponível em:

https://repositorio.ul.pt/bitstream/10451/28662/1/Covas_Veiga_AcademicEngagement.pdf. Acessado em: 04 nov 2019.

DAL-FARRA, Rossano André; LOPES, Paulo Tadeu Campos. Métodos mistos de pesquisa em educação: pressupostos teóricos. Nuances: estudos sobre Educação, Presidente Prudente, v.24, n.3, p.67-80, 2013. Disponível em : http://revista.fct.unesp.br/index.php/Nuances/article/view/2698/2362. Acessado em: 16 mar 2020.

DALL 'ORTO, Hilda Léa Rabello. Do professor técnico ao professor reflexivo: contribuições e limitações da didática e da prática de ensino na formação docente em química. 1999, 103p. Campinas: Dissertação (Mestrado em Educação) - Unicamp, Campinas, 1999. Disponível em: http://repositorio.unicamp.br/bitstream/REPOSIP/250892/1/Dall\%27Orto_HildaLeaRabello_ M.pdf. Acessado em: 04 nov 2019.

DECI, Edward L.; RYAN, Richard M.; Handbook of self-determination research. $1^{\text {a }}$ edição. Rochester: University of Rochester Press, 2002.

DECI, Edward L.; RYAN, Richard M. Intrinsic motivation and self-determination in human behavior. $1^{a}$ edição. New York and London: Plenum, 1985.

DORIGON, Thaisa Camargo; ROMANOWSKI, Joana Paulin. A reflexão em Dewey e Schon. Revista Intersaberes, Curitiba, v.3, n.5, p.8-22, 2008. Disponível em:

https://www.uninter.com/intersaberes/index.php/revista/article/view/123/96. Acessado em: 04 nov 2019. 
ENGELMANN, Erico. A motivação de alunos dos cursos de artes de uma universidade pública do norte do Paraná. 2010, 127p. Londrina. Dissertação (Mestrado em Educação), UEL, Londrina, 2010. Disponível em:

http://bdtd.ibict.br/vufind/Record/UEL_5d7e214b582699fa20cd69ebb649adc2. Acessado em: 04 nov 2019.

FERREIRA, Luiz Henrique; KASSEBOEHMER, Ana Cláudia. Formação inicial de professores de química: a instituição formadora (re)pensando sua função social. $1^{\mathrm{a}}$ edição, São Carlos: Pedro \& João Editores, 2012.

FREITAS, André Luís Policani; RODRIGUES, Sidilene Gonçalves. A avaliação da confiabilidade de questionários: uma análise utilizando o coeficiente alfa de Cronbach. In: SIMPEP, 12, 2005, São Paulo, Anais...São Paulo: UNESP, 2005, p.1-14. Disponível em: https://www.researchgate.net/publication/236036099_A_avaliacao_da_confiabilidade_de_que stionarios_uma_analise_utilizando_o_coeficiente_alfa_de_Cronbach. Acessado em: 04 nov 2019.

GUIMARÃES, Sueli Edi Rufini. Avaliação do estilo motivacional do professor: adaptação e validação de um instrumento. 2003. 188p, Campinas: Tese (Doutorado em Educação) Unicamp, Campinas, 2003. Disponível em:

http://bdtd.ibict.br/vufind/Record/CAMP_558667b7e6f793b11fd8801c5dc02a78. Acessado em: 04 nov 2019.

HAN, Byung-Chul. Sociedade do cansaço. $2^{\text {a }}$ edição, Petrópolis: Vozes, 2015.

OLIVEIRA, Roberto Dalmo Varallo Lima de; QUEIROZ, Gloria Regina Pessôa Campello. A formação de professores de ciências a partir de uma perspectiva de Educação em Direitos Humanos: uma pesquisa-ação. Ciência e Educação, Bauru, v.24, n.2, p.355-373, 2018. Disponível em: http://www.scielo.br/scielo.php?pid=S151673132018000200355\&script=sci_abstract\&tlng=pt. Acessado em: 04 nov 2019.

ORGANIZAÇÃO MUNDIAL DE SAÚDE. Suicide in the world: Global health estimates, 2019. Disponível em: https://apps.who.int/iris/bitstream/handle/10665/326948/WHO-MSDMER-19.3-eng.pdf?ua=1. Acesso em 15 de outubro de 2019. Acessado em: 04 nov 2019.

RAZERA, Julio César Castilho; MATOS, Carla Maria Santana; BASTOS, Fernando. Um perfil métrico das pesquisas que destacam a formação de professores na área brasileira de educação em ciências. Investigações em Ensino de ciências, Porto Alegre, v.24, n.1, p.200222 2019. Disponível em: https://www.if.ufrgs.br/cref/ojs/index.php/ienci/article/view/1244. Acessado em: 04 nov 2019.

RÔÇAS, Giselle; ANJOS, Maylta Brandão dos.; PEREIRA, Marcus Vinicius V. Quanto vale ou é por quilo: o peso da publicação acadêmica na área de ensino. Ensino e Tecnologia em revista.Londrina, v.1, n.1, p.46-66, 2017. Disponível em:

https://periodicos.utfpr.edu.br/etr/article/view/5949. Acessado em: 04 nov 2019.

ROMÃO, José Eustáquio. Avaliação neoliberal e avaliação contra-hegemômica. Revista Teias, Rio de Janeiro, v.20, n.56, p.362-374, 2019 Disponível em: https://www.epublicacoes.uerj.br/index.php/revistateias/article/view/36167. Acessado em: 04 nov 2019. 
SOUZA, João Valdir Alves de Souza (Org). Formação de professores para a Educação Básica: dez anos da LDB.1 ${ }^{a}$ edição. Belo Horizonte: Autêntica, 2007.

TOLEDO, Evelyn Jeniffer de Lima Toledo. Estudo da correlação entre motivação, estilo de aprendizagem e os tipos psicológicos junguiano. 2015. 132f, São Carlos: Tese (Doutorado em Química)-UFSCar, São Carlos, 2015. Disponível em:

https://repositorio.ufscar.br/bitstream/handle/ufscar/7237/TeseEJLT.pdf?sequence=1. Acessado em: 04 nov 2019.

TOLEDO, Evelyn Jeniffer de Lima Toledo; COUTINHO, Henrique do Nascimento; GALDINO, Alessandra dos Santos. Saúde Mental em um curso do Licenciatura em Química: a crise na Universidade. In: ENPEC, 12, 2019, Natal, Anais...Natal: UFRN, 2015, p.1-7. Disponível em: http://abrapecnet.org.br/enpec/xii-enpec/anais/resumos/1/R0857-1.pdf. Acessado em: 04 nov 2019.

Recebido em: 07 de novembro de 2019. Aprovado em: 23 de março de 2020. 